\title{
The analysis of LCA environment material evaluation
}

\author{
Guogang $\mathrm{Li}^{\mathrm{a}}$, Ting Yang ${ }^{\mathrm{b}}$ and Jiaying Zhou ${ }^{\mathrm{c}}$ \\ School of Tianjin Technology University, Tianjin 300384, China \\ a1099828185@qq.com, bzjywanx@163.com, '578478183@qq.com
}

Keywords: Environmental material, LCA, evaluation analysis.

\begin{abstract}
Material environment performance will become a basic performance of new materials in the 21stcentury, various environmental materials and the development of green products will become a dominant direction of the development of the material industry. Life cycle assessment (LCA) has developed into key tools of a system to evaluate the environmental impact of product whole life cycle process. In this paper, based on the LCA to evaluate and analysis the ecological environment material, and introduce the evaluation system and method of environmental materials and design principles.
\end{abstract}

\section{The concept and features of environmental materials}

\subsection{The definition of environmental material}

Environmental material is also known as environmental awareness, is at the same time has satisfactory performance and good environmental coordination, or is the material that can improve the environment. Namely those have good performance or functions, and the consumption of the resources and energy is less and the pollution of the ecological and environmental is less. It is good at human health, High biodegradable or renewable utilization. In the whole process of preparing, using, wasting and recycling, and the environment coordinated coexistence of all kinds of materials. Therefore, Environmental material is endowed with traditional structural materials and functional materials with special excellent environment coordination of materials, to get by the material workers developing new materials or improving, transforming traditional materials under the guidance of environmental consciousness.

\subsection{The characteristics of environmental material}

According to the definition, environmental materials should have three obvious characteristics, the first is the use of good performance; Secondly, high resource utilization; the third is don't having side effects to the ecological environment.

\section{Ecological material application research status}

The ecological environment material is maintaining the balance of ecological environment of human settlements and cleansing the living space. It is to purify the environment and repair the ecological environment andpromote human body health and other function. Materials scientists proposed the concept of "ecological environment material"' in the 1990s, immediately getting consensus around the world. In china, "863 plan"and "973 plan" will also be listed as one of the key research direction in the ecological environment materials.

Application research on the ecological environment material: development environment compatibility of new materials and their products and coordination to improve the existing material environment, is the main content of environmental materials applied research. So far, in the pure natural materials, biological materials and green packaging materials, development and application of ecological building materials and so on have great progress. In the application of the ecological environment material study, the development of ecological building materials is one of the main aspects, such as water soluble coatings, powder coatings, solvent-free coatings, used for sanitary ceramics coating on the surface of the material, etc. At present, a lot of research on the ecological environment material, mostly in the guarantee under the condition of the using of the material has satisfactory performance, try to reduce the burden on the environment in the process of processing 
and use of, or to save resources, reduce energy consumption. In other words, it is mainly concentrated on the terms of materials processing technology.

\section{Evaluation of environmental material}

Material evaluation system and method of environmental load is an important content of environmental material, the research and application helps people to objectively evaluate the material, for the development of new materials and reforming the traditional materials provide new train of thought. Evaluation method of environmental material essence can be divided into two categories: one kind is used for material development and production of process evaluation, the process is more complex, such as life cycle assessment (LCA); Another kind is the consumer environment material evaluation system, Having the popularity, universality, such as "material regeneration recycling degree evaluation and system", etc.

\subsection{Life cycle assessment and its approach}

Life cycle assessment (LCA), that is, a quantitative evaluation of product (or service) system, manufacturing engineering, was obtained from the extraction of raw materials or used to waste treatment and recycling use of input and output of the whole process of life and the environment influence (as shown in figure 1). It comes from the United States in 1969 the Coca-Cola Company to its beverage container to carry out the comparative study of optimizing material and shape of container. Now has developed into a standardized product environmental impact assessment and environmental management approach. The international organization for standardization has successively issued ISO14040 life cycle assessment, principles and framework) and ISO14041 life cycle assessment, inventory analysis, in addition, ISO14042 life cycle assessment - 15014043 life cycle impact assessment and evaluation a definition has been completed. It is forthcoming.

According to ISO14040, LCA analysis steps including purpose and scope, definition, inventory analysis, impact assessment and improvement evaluation (figure 2).

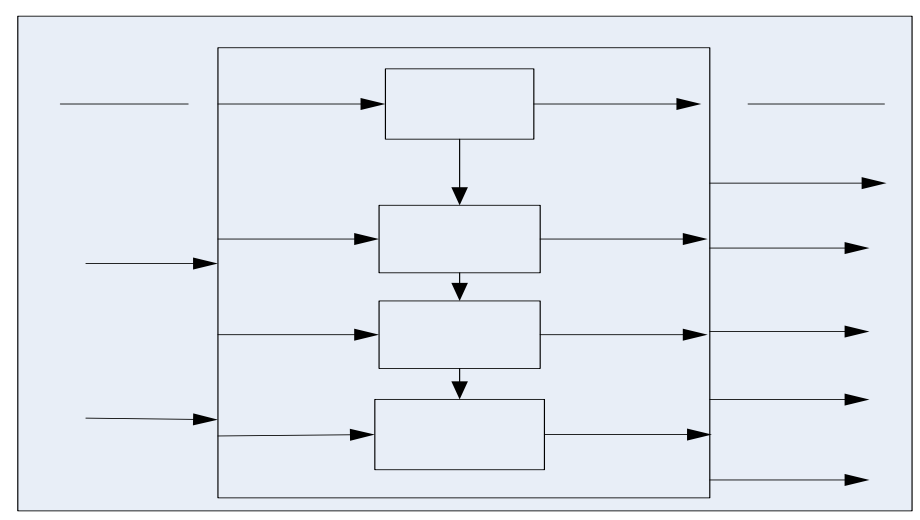

Fig. 1 The framework of life cycle assessment work

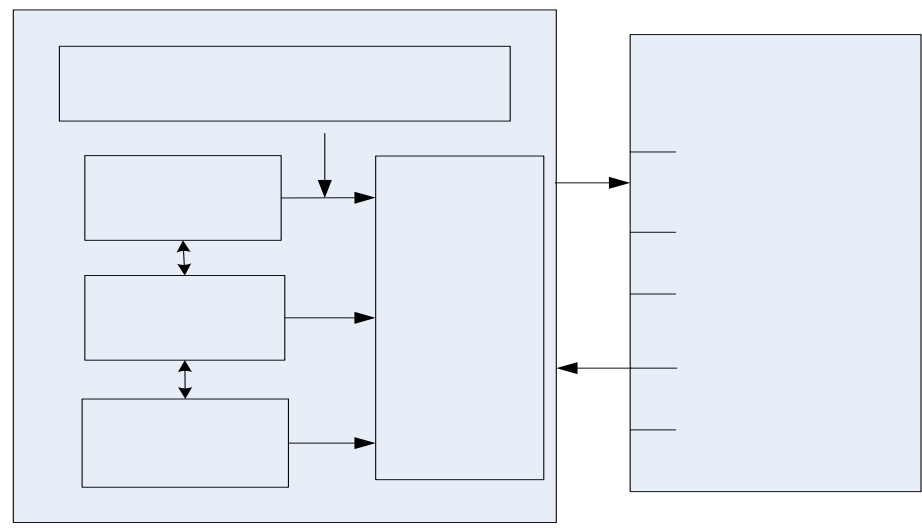

Fig.2 Life cycle assessment steps 


\subsection{LCA evaluation of materials}

Quantitative evaluation of environmental performance of materials is an important content of environmental materials development and evaluation. Quantitative evaluation material of LCA is mainly on the material system from raw material stage to the final waste out of the whole process of environmental impact (resource, energy and emissions), a comprehensive evaluation for the life of the material evaluation period.

The exact makeup of LCA is cataloging analysis (Inventory analysis) and damage evaluation (Impact assessment), interpretation (Interpretation), referred to as $3 \mathrm{I}$. For a process by the method of LCA, establishing its mathematical model method is more popular with the weighted factor method and linear programming method, etc.

Weighting factor method. Weighted factor method is for a product or process production of resources, energy, and the factors such as define a normalization factor, obtained by using the method of weighted average to get the event environment load size.

Linear programming method. Linear programming method is commonly used in the systematic analysis of the evaluation of technology, to study in some limited conditions how to achieve the goal of the most effective. The linear programming mathematical form is as:

Solving $x_{j}(j=1,2,3 \cdots, n)$ satisfies the constraint conditions:

$\sum_{\mathrm{j}=1}^{\mathrm{n}} a_{i j} x_{j} \leq b_{i}(i=1,2,3 \cdots m)$ and $x_{j} \geq 0(j=1,2,3 \cdots n)$

And make the objective function: $f=\sum_{\mathrm{j}=1}^{\mathrm{n}} c_{i} x_{j}$ maximum or minimum value.

For environmental materials, the quality criterion, economic criterion and time criterion, criterion of resources, the energy criterion and environmental criteria in a certain criterion as the objective function, some criterion as constraint conditions, can form a series of linear programming problems. As a result, the linear programming method in combination with input and output method and weighted factor method, on the basis of through a linear function to describe the process of a product or process environmental impact.

\section{The principle of environmental material design}

The traditional material designs to consume a large amount of energy and resources, produce a large amount of waste to get the cost of materials of high performance, high yield and low cost. To the design of the environment material, consider not only the material of various performance requirements, but also material impact on the environment. Therefore, the environment performance of the material design emphasized in keeping the basic unchanged under the premise of maximize the use of material resources and save energy, should follow the following a few basic principles:

(1)As far as possible using earth abundant element or take substance as a group of constituent element.

(2)As far as possible using elements have small impact on the environment.

(3)As far as possible reducing the materials’ content of intensifying elements.

(4)As far as possible minimizing the element types;

(5)As far as possible using elements of the same kind or material as the strengthening of the second phase composite materials

(6) In principle, don't add cannot be refined from the elements at present.

The design train of thought environmental materials is in the pursuit of material of high-performance at the same time stressed the multi-purpose, is diversity and specialty of traditional materials pursues updating and development of ideas. Based on the energy strategy in resources, make full use of the heat treatment ways to adjust the material performance, having been successfully used in the design of environmental material. Japan developed the type of alloy at least. To meet the need of multipurpose super universal alloy (such as Fe-Me-Si-C steel) is a kind of typical environmental material. From the perspective of environmental materials, the materials of the 
ecological transformation, "super clean, super fine and homogeneous" of the development of high-performance materials and high strength and long life of materials, zero emissions, zero waste and comprehensive utilization of solid waste, is a research hotspot in the field of the material. Recycling of materials design is the foundation of environmental material design and guiding principles, For metal materials, it is easy to be the basic principle of recycling is reducing the alloy elements and adjusting in order to keep its high performance and microstructure as alternative methods of adding alloying elements to obtain the required performance, easy separation and no secondary pollution during the process of regeneration. For composite materials, it's principles of is easy to recycle is a single component instead of the multiphase components, easy to break down, or to degrade waste, can be repeatedly recycled.

\section{Conclusions and recommendations}

(1) Life cycle assessment (LCA) is a system to evaluate the product material impact on the environment (burden) of good methods, development of the ecological environment material basis and important tool.

(2) Inventory analysis, especially the data collection and its representative is the key of the LCA, because of differences of technology and management level, poor data information sharing, our country should adopt Japan operation pattern, collaboration facilitated by industry association, to be responsible for the organization to collect input and output data in the industry, with related products' (material) input and output and environmental burden of data collection and validation work.

(3) LCA software system and its database development is the basis and important direction of LCA study, we should actively absorb advanced foreign experience, to develop a suitable to China's national conditions, and can match with the current financial system, and the material resources management information system and computer integrated system (CIMS) fusion products LCA system and its environment information management system, make it become an important part of enterprise comprehensive management.

\section{References}

[1]Xiao Dingjin, Wang Yongchuan. The technical framework of material cycling system (LCA) assessment [J].Materials review, 1995 (3):12-13.

[2] Rosy W C, Navin-Chandra D, Kurfess T, et al. A systematic metrology of material selection with environmental considerations, IEEE, 1994:252-257.

[3] Wang Bolu. The difficulty and realistic way of sustainable development [J].World environment, 1998 (2):31-34.

[4]Weule H. Life-cycle analysis element for future products and manufacturing technology, Annals of the CIRP.1993, 42(1):181-184.

[5] Wang T M, Xu J C, Zuo T Y. Journal of Lanzhou University[J].1996, 32(Sup): 102- 109.

[6] W. Strunk Jr , E.B. White, The Elements of Style, third ed., Macmillan, New York, 1979.

[7] Huang S J, Huang T S, Liu D C. Introduction of philosophy of science and technology natural dialectics in revolutionary times of S\&T[M]. Beijing:Chinese People University Press, 1986.

[8]ISO.ISO/CD/14040: Life Cycle Assessment-Principles and Guidelines.Geneva: International Organization for Standandization, 1997. 